\title{
Augmented Reality based Adaptive and Collaborative Learning Methods for Improved Primary Education Towards Fourth Industrial Revolution (IR 4.0)
}

\author{
A F M Saifuddin Saif ${ }^{1}$ \\ Department of Computer Science \\ American International University -Bangladesh
}

\author{
Zainal Rasyid Mahayuddin², Azrulhizam Shapi'i ${ }^{3}$ \\ Faculty of Information Science and Technology \\ Universiti Kebangsaan Malaysia \\ 43600 UKM, Bangi, Selangor, Malaysia
}

\begin{abstract}
Existing primary education is not organized properly to fulfil the demand of fourth industrial revolution (IR 4.0) which causes lack of engagement in learning materials, lack of spatial ability and motivation towards learning by young age students. Students especially from initial education level tend to learn from seeing rather than reading or memorizing. In this context, technology like augmented reality and virtual reality bears such visual power in lieu with interactivity and engaging characteristics by bringing virtual and real world together. In addition, flexible presentation mechanisms in lieu with tagging and tracking technology with various degree of freedom provide the effective ground of augmented reality and virtual reality to integrate with current primary education or initial level of education. In this context, this research presents comprehensive and critical reviews in the previous research in terms with several aspects such as methods, research design and experimental validation. Each of the aspects is demonstrated with adequate advantages and disadvantages to design the integration of augmented reality and virtual reality with primary education methodology. In addition, this research illustrates extensive critical explanation for various challenges to integrate augmented reality and virtual reality with primary education to make students motivated towards education, effective activity and memorization with visualization. The overall investigation proposed in this research is expected to fulfil the future demand for Fourth Industrial Revolution (IR 4.0).
\end{abstract}

Keywords-Augmented reality; virtual reality; adaptive and collaborative learning; fourth industrial revolution

\section{INTRODUCTION}

Education is a continuous learning process which should include not only traditional class activities, learning process should be creative and interactive to meet the demand of fourth industrial revolution (IR 4.0) so that students will not feel demotivated towards learning. Besides, way of acquisition of education should be through discussion, research, training which should be fun and interesting. However, current initial level of education system seems to abandon the main idea about education and learning process to lean towards memorizing and rote learning. Traditional primary education is based on two-dimensional materials and does not provide any of these opportunities. Children aged from 5-11 are the ones who goes to primary schools and considered to be future hope, are losing their hope from learning. As a result, dropout rates are growing day-by-day and students are lacking behind in lieu with not being able to show their creativity. To keep the children focused, motivated, creative and to keep their enthusiasm alive, changes needs to be brought in the way of delivering education to the children which demands to opt for technology integration with primary education. To integrate technology with primary education, researchers need to take account more on visualization and boosting engagement of students. Technology with such visualization power as well as interactivity is Augmented Reality, which bring virtual and real world together by putting digital information on the world. Existing research has been engaged in finding ways to integrate augmented reality with education system and achieved positive results. However, most of them were integrated with college or higher studies. Previous research on augmented reality with education medium and positive results so far gained by the previous research encourage this research to depict critical and comprehensive reviews to integrate augmented Reality with primary education system.

Augmented Reality and virtual reality is an advanced technology which connects virtual and physical world around us by superimposing digital information like sound, images or objects which can be seen with the help of regular handheld devices like mobile phones, tablets, laptops. All the positive characteristics of augmented reality make it dynamic and perfect combination for technology-based education system. Students from primary education tend to learn things by visualizing not reading or memorizing them. Augmented Reality is perfect medium in this context which provides a great deal of visualization with digital information as well as let students interact with the system so that contents can be taught in groups. AR in classroom is expected to be helpful to capture student's attention towards the learning and make them feel more engaging with other students and teacher as well [1] due to some factors, i.e. enhance environment and help with discovery-based leaning and increased student's spatial ability and motivate them towards learning. This research aims to illustrate various methods in terms with integrating AR technology with primary education level.

For the opportunities provided by augmented reality and virtual reality, AR has been used in college and higher education level in the previous research. The results from their researches illustrates that augmented reality and virtual reality has shown a promising result, better understanding of the 
subject, boost engagement among students with course material, improve of interest and attention in classroom which can play motivating factors to mix augmented reality in primary education. This research presents critical and comprehensive reviews of using augmented reality in the exiting research towards using augmented reality in primary education. Section 2 presents core research background, Section 3 demonstrates comprehensive and critical reviews based on existing methods, Section 4 illustrates existing research based on frameworks, Section 5 depicts experimental validation by the previous research, Section 6 describes observation and discussion and finally, concluding remarks are presented in Section 7.

\section{CORE BACKGROUND STUDY}

Existing education system is not structured properly to meet the demand of fourth industrial revolution (IR 4.0) and its hampering society in a lot of ways, i.e. students are not feeling motivated, not curious about learning, tired of memorizing and reading books when they cannot grasp and there is no alternative to it. Education sharpens the way to future and it's important to work for the betterment of education. But it's not easy to improve education system in a short time where all issues need to address properly for proper structured education methodology and will provide solutions to most of the problems as well as will not become outdated within a short period of time. Making education better with technology, researchers are continuously conducting researches and they have come up with the technology called Augmented Reality [2]. For the last few decades research has been going on the possibilities of Augmented Reality in education system and most of the researches have been conducted on higher level of education to teach different subjects and measuring its success based on some key factors, i.e. students motivation towards learning, engagement with materials, concept understanding, visualization for enhancing spatial abilities, grasping deeper understanding of abstract and difficult topics [3]. The result of the research was positive and successful in terms of achieving the satisfactory level of students and teachers. Augmented Reality has provided students with new techniques of visualizing course materials, new way of interacting with course materials within the class, changing their perspective of learning and increasing their interest to the courses.

Augmented reality and virtual reality have all the characteristics needed to improve our current education system and give education the pace it needs to be mixed with the technology. Existing research showed how to implement augmented reality with education system to improve education's current situations. In Turkey it is very difficult to achieve good results in Ottoman Turkish reading but with AR technology they have found that students have less difficulty and performed well in terms of performance [30]. Medical Subjects need much deeper understanding and they are facing problems especially in generating real life scenarios but using Miracle [5], an AR system it was possible to make real life scenarios and provide students with an interactive virtual human body where they can explore for their better understanding. Similarly, there are a lot of augmented reality applications which are being used to taught different subjects to students in different countries. Augmented Reality are used in medical education [6,7], science [8,9], engineering [10,11], object detection [12,13,14], motion modelling [15,16,17], face modelling [18,19], analysis of aerial images [20,21,22] etc. and a few mentionable Augmented reality applications are Elements 4D, Experience Chemistry teach chemistry, Anatomy 4D, Human Heart 3D and Corinth Micro Anatomy teach human anatomy, CARE an Augmented Reality application built to teach Science, Technology, Engineering and Math parts. ARVe - Augmented Reality applied to vegetal field [23], FreshAirTM teach discovery-based learning [24], Construct 3D to teach math (geometry) to college students [25], AR Physics to teach physics to college students [26]. All these AR applications are really making some differences to engaging students and their motivation. However, all of these existing AR applications are for college or higher-level study materials.

Augmented reality has also been used in primary level education but the usage is really few, yet the results are positive. Augmented Reality Popup Book application which was used to teach English Language and the course material were built according to English curriculum [27]. Realitat3 is an augmented reality system consists of six applications: skeletal apparatus, water cycle, plant development, frog metamorphosis, solar system and the senses. All these AR applications are being used to teach primary school students to improve their efficiency (academic achievement), usability and motivation [28]. Again, researcher in [27] explored the possibility of augmented reality application in teaching English to primary school children. Research in [29] was conducted to discover the geometrical disadvantages of technology for implementing augmented reality in education, the result illustrates positive feedback and promising output. The application was one mouse per children and it teaches math to students. Research in [1], opt for different methodologies to figure out which will work best for integrating augmented reality with primary education system. Other business applications which were built for primary education, i.e. Math alive teaches math's up to 3rd grade students, Animal Alphabet AR Flashcards are built to learn letters, Zookazam or Bug 3D to teach about animal species. However, there are few applications which can be incorporated with the curriculum provided for primary education level children. Existing experimental results for various AR applications are remarkable to prove enough that AR can not only be incorporated with primary education system but also it is well acceptable by teachers, students, parents as well. In addition, existing usage of augmented reality has showed better engagement with learning contents, more attentive and faster learning.

\section{REVIEW BASED ON METHODS}

Although currently we are living in three-dimensional era, however two dimensional materials is still provided to use for education which is failing us to provide quality education to keep our pace with modern era. To keep up pace with modern era we need to embedded technology with education and many countries are doing so, and the result indicate positive and better impact on learning. Researcher has been doing so many experiments and testing many approaches to integrate 
technology with education for quality education so that they could find the optimal and best solution possible to integrate Augmented Reality with education system. However, finding organized procedure which can help us to integrate technology with our education system as well as work smoothly with our existing educational system is not an easy task but with hard work and depth research, researchers have also come up with some effective procedures which have shown how fun and amazing education can be with help of augmented reality. Existing methods in this context are shown in Fig. 1.

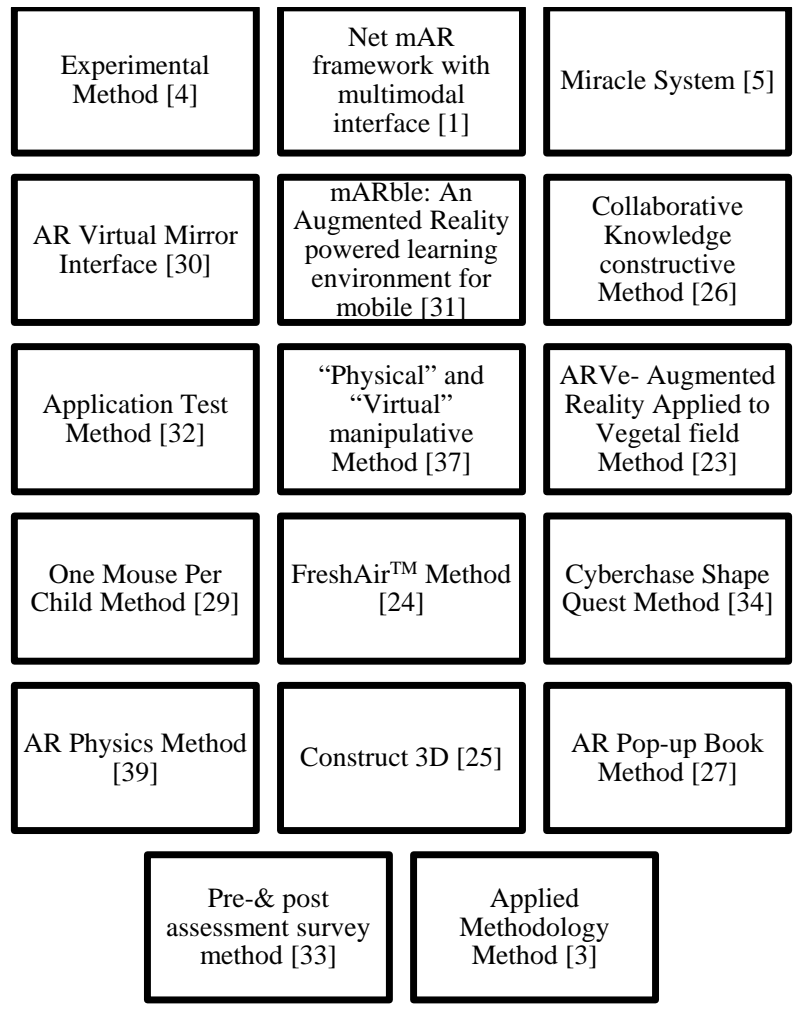

Fig. 1. Existing Learning Methods using Augmented Reality.

Augmented reality is highly praised due to its visualization capacity and interactive capacity with the system [1]. Researcher in [1] proposed multimodal interface model as mobile augmented reality framework using these dynamic characteristics of augmented reality. Their proposed system is built for mobile version in hope of increasing interactivity which will boost the engagement of students with the learning materials and increased the accessibility of augmented reality based educational material through application. However, their proposed method is still no acting as hypothesis as their proposed method is not implemented. Weakness of multimodal interface model can be improved by Construct 3D, a collaborative learning method.

Construct 3D method was introduced to overcome its drawback and flows of multimodal interface model which was theoretical hypothesis. Construct 3D method is based on the interactivity characteristics and have modified the characteristics by creating various interactive model to teach students about geometry and increase their spatial ability [25]. Construct 3D method also increased student's interaction with system and for various model of interactivity in lieu with providing more engagement with course materials. However, construct 3D method was designed to teach geometry only to students. To overcome the disadvantage of construct 3D method, AR mirror interface method was introduced. AR mirror interface model was proposed to study the affordance of augmented reality in education, proposing a less expensive and more user interactive tool [30]. Although, AR mirror interface model was successful to fulfil its purpose, AR mirror interface model required more engagement of students to teach some subjects than tradition educational methodologies. To fill the gap created by AR Mirror interface another method was introduced Realitat3.

Realitat3 is a method proposed for increasing interaction between system and user while keeping the affordance in AR system which consists of six AR games: skeletal apparatus, water cycle, plant development, frog metamorphosis, solar system and the senses. Realitat3 introduced AR gaming for educational purpose and more engagement while keeping student motivated, interested towards learning [28]. However, Realitat3 method is not able to teach all subjects by games which can be overcome by collaborative knowledge construction method using AR.

Collaborative knowledge construction method integrated augmented reality to help learners to develop skills and knowledge effectively, enabled co-located learners to be involved in knowledge construction by exploring the outside environment and interacting with each other through the guidance of AR-supported information [26]. However, software usability or learners perceived as learning effectiveness of the AR system needs to improved more for collaborative knowledge construction method using AR. To overcome this issue, research in [5] came up with Miracle System.

Research in [5] explored the possible areas of integrating augmented reality with medical study to give medical students a better way to learn medical studies. They focused on the visualization power of augmented reality as medical subjects especially Anatomy which needs figure to get a better understanding. Anatomy is a topic where students are taught the internal structures of human body so that they can have a deeper knowledge about human body and how organs work. To match with anatomy characteristics research in [5] introduced Miracle system which displays anatomical structures of the user's body to a monitor and they have also proposed a gesture-based interaction to get real life experience. However, their proposed research was only for anatomy study and focused on a small number of important organs of the abdomen. For the usage of large screen and in order to solve the portability issue research in [31] proposed a portable augmented system called mARble.

Research in [31] proposed mARble which was an augmented reality powered learning environment for mobile proposed to make augmented system portable and affordable to use. As most of the students carry smartphone with them and now smartphone have enough computing power to carry out the operations of augmented reality. They tried to make students smartphone alternative of their books. They aimed for portability and making it as an alternative of books to teach 
basic medicine courses. Using their system medical students performed better than those who were taught using books. Their performance was measured in terms of "the hedonic qualities simulation (HQ-S), identification (HQ-I) and attractiveness (ATT)". However, their proposed system was used only for teaching basic courses in legal medicine which is the drawback of their method and solved by research in [27].

Research in [27] introduced AR pop-up Book to solve the content issue which was faced by most of the previous research methods. They integrated augmented reality with the book we read where users need to scan the image with the smart phone and augmented contents will appear on their mobile screens. They used AR pop-up Book to teach physics to the students which also needs deeper understanding. AR pop-up books help the students to bridge the gap between the digital and physical world. However, drawback of their method was that their proposed method was tested with 5 students only, so the results gained by AR pop-up Book may not be same for large number of users. In this context, research in [32] came with the solution by proposing Applied Test Method.

Applied Test Method experimented how augmented reality can be used in education with large number of participants [32]. Research in [32] proposed Applied Test Method to display real time results on screen, designed for educational purposes, interactive features like reactive to plain paper notebooks. However, their proposed methods provides some concerns towards privacy and ethical concerns, social acceptance concern of being constantly photographed, videotaped. Even though Applied Test Method was designed for education, however, it seems that Applied Test Method lacks effectiveness when used with high-achieving students which indicates little impact on high-achieving students. To solve this weakness, research in [33] introduced Pre-\& Post Assessment Survey Method.

Research in [33] worked with how augmented reality can provide quality education in terms with delivering lessons to the students. They proposed Pre-\& Post Assessment Survey
Method where they gathered students, teachers' feedback with traditional and augmented reality based educational system. They took an assessment before and after use of augmented reality and analyzed results. According to their survey, they were able to achieve better understanding level for spatial concepts and make learning more effective and interactive. However, they implemented their research on students who were in grad 6 to 8 only. To investigate more about the spatial ability improvement with augmented reality, research in [34] proposed Cyberchase Shape Quest method.

Research in [34] introduced Cyberchase Shape Quest Method to improve spatial ability with augmented reality. Their goal was to utilize augmented reality to teach geometry as this particular subject needs more spatial ability to grasp the problem. With their proposed method they saw students became engaged with spatial memory, visualization for seeing the content and planning to solve the given task which showed that their method was more interactive, engaging and efficient. However, their method can only teach students about geometry which is a major drawback. To solve this problem, research in [4] introduced Experimental Method. Experimental method was introduced to overcome the issue and crisis defined by other methods. In this method, research in [4] tends to select a study group to gathering their feedback after using the system and monitor the results. So far experimental method gives the best output with positive result and great motivation to leaning [4]. Previously, many methods were tested to integrate AR with educational methodology to have a positive and good impact on engaging students, boosting their interactivity. Existing concerns by the researchers proves that augmented reality can be integrated with primary education system for improved and adaptive learning technique. However, existing almost all the methods needs further investigation due to the lack of experimentation on larger number of users, portability issues, user friendliness, higher engagement of the students. Previous research methods with advantages and disadvantages for integrating augmented reality to improved existing education methodology are mentioned in Table I. 
TABLE I. Previous Proposed Methods with AdVANTAge and Disadvantage

\begin{tabular}{|c|c|c|}
\hline Method Name & Advantage & Disadvantage \\
\hline Experimental method [4] & $\begin{array}{l}\text { So far best output with positive result and great motivation to } \\
\text { leaning. }\end{array}$ & $\begin{array}{l}\text { The experiment was conducted on } 60 \text { students and limited } \\
\text { words. The result might be different for large group of } \\
\text { students and syllabus }\end{array}$ \\
\hline $\begin{array}{l}\text { Net mAR framework with } \\
\text { multimodal interface [1] }\end{array}$ & $\begin{array}{l}\text { Using Multimodal Interface, usability of application increases } \\
\text { as people can interact with the app. }\end{array}$ & Only theoretical method proposed. \\
\hline Miracle system [5] & $\begin{array}{l}\text { (a) Displayed anatomical structures on user's body, (b) New } \\
\text { concept for gesture-based interaction. }\end{array}$ & $\begin{array}{l}\text { Their method was used for only anatomy of small number } \\
\text { of important organs of the abdomen. }\end{array}$ \\
\hline AR Virtual Mirror Interface [30] & $\begin{array}{l}\text { (a) Studied affordance and contains of AR technology in } \\
\text { formal education, (b) Showed AR virtual mirror is less } \\
\text { expensive and more users can interact with it, (c) Showed how } \\
\text { to improve AR to integrate with national curriculum of UK } \\
\text { Primary education }\end{array}$ & $\begin{array}{l}\text { (a) Students using AR were less engaged than those using } \\
\text { traditional resources, (b) Only used to teach science }\end{array}$ \\
\hline $\begin{array}{l}\text { mARble: An Augmented Reality } \\
\text { powered learning environment } \\
\text { for mobile[31] }\end{array}$ & $\begin{array}{l}\text { Performed better than text book in terms of "the hedonic } \\
\text { qualities simulation (HQ-S), identification (HQ-I) and } \\
\text { attractiveness (ATT) }\end{array}$ & Applicable only for basic course in legal medicine. \\
\hline AR in education [35] & $\begin{array}{l}\text { (a) AR system detected students' locations and working status, } \\
\text { (b) Provided task reminders, (c) Offered alternatives to } \\
\text { refocus students' attention, (d) Enhance students' recognition } \\
\text { of community of learners }\end{array}$ & $\begin{array}{l}\text { (a) Students often felt overwhelmed and confused when } \\
\text { they were engaged in a multi-user AR simulation. (b) } \\
\text { Students require applying and synthesizing multiple } \\
\text { complex skills in spatial navigation, collaboration, problem } \\
\text { solving, technology manipulation, and mathematical } \\
\text { estimation. }\end{array}$ \\
\hline $\begin{array}{l}\text { Collaborative knowledge } \\
\text { construction [26] }\end{array}$ & $\begin{array}{l}\text { (a) Helped learners to develop skills and knowledge } \\
\text { effectively. (b) Enabled co-located learners to be involved in } \\
\text { knowledge construction by exploring the outside environment } \\
\text { and interacting with each other through the guidance of AR- } \\
\text { supported information. }\end{array}$ & $\begin{array}{l}\text { Software usability needs to be improved for effectiveness } \\
\text { of the AR system. }\end{array}$ \\
\hline Application Test Method [32] & $\begin{array}{l}\text { (a) Displayed real-time result. (b) Designed for educational } \\
\text { purposes, interactive features reactive to plain paper } \\
\text { notebooks. }\end{array}$ & $\begin{array}{l}\text { Causes privacy and ethical concerns in lieu with social } \\
\text { acceptance of being constantly photographed, videotaped, } \\
\text { and analyzed, less effectiveness when used with high- } \\
\text { achieving students. }\end{array}$ \\
\hline $\begin{array}{l}\text { "Physical" and "Virtual" } \\
\text { manipulative [37] }\end{array}$ & $\begin{array}{l}\text { Showed that students motivation can be increased through AR } \\
\text { technology. (b) Children who cannot yet think symbolically, } \\
\text { AR play vital role in that context. }\end{array}$ & $\begin{array}{l}\text { AR experiences may allow students to view virtual content } \\
\text { and other people in the same mixed-reality space. }\end{array}$ \\
\hline $\begin{array}{l}\text { ARVe - Augmented Reality } \\
\text { applied to Vegetal field [23] }\end{array}$ & $\begin{array}{l}\text { (a) Used for students with cognitive disabled, (b) Provided } \\
\text { feedback from the students, teachers and parents. }\end{array}$ & Worked only in the basis of visualization and matching. \\
\hline $\begin{array}{l}\text { Case Study of AR in Primary } \\
\text { School [28] }\end{array}$ & $\begin{array}{l}\text { An evaluation of the educational contents was made from the } \\
\text { point of view of efficiency (academic achievement), usability } \\
\text { and motivation }\end{array}$ & $\begin{array}{l}\text { Depends on work which was conducted between } 1993 \text { and } \\
2007\end{array}$ \\
\hline One Mouse Per Child [29] & $\begin{array}{l}\text { (a) The system can be implemented even with different } \\
\text { environment condition with minimal equipment, (b) } \\
\text { established statistically relevant } \\
\text { results and observed that the software proved most beneficial } \\
\text { for the students with the lowest } \\
\text { initial results. }\end{array}$ & Only teaches math to primary school children. \\
\hline FreshAir $^{\mathrm{TM}}[24]$ & $\begin{array}{l}\text { Navigated the pond environment and observed virtual media } \\
\text { information overlaid on the virtual pond }\end{array}$ & $\begin{array}{l}\text { The system was built for outdoor study, there was no } \\
\text { indication how it will integrate with indoor technology. }\end{array}$ \\
\hline Cyberchase Shape Quest [34] & $\begin{array}{l}\text { While using the application students engaged their spatial } \\
\text { memory, visualization \& planning skills. }\end{array}$ & Focused only on geometry. \\
\hline AR Physics [39] & $\begin{array}{l}\text { (a) Initial step toward understanding learners' knowledge } \\
\text { construction process by using AR System, (b) Learners } \\
\text { knowledge construction behaviors were qualitatively } \\
\text { identified according to adaptive three-category coding scheme. }\end{array}$ & $\begin{array}{l}\text { Focused only in the performance on learners' knowledge } \\
\text { construction of elastic collision of physics. }\end{array}$ \\
\hline $\begin{array}{l}\text { Differentiate between learning } \\
\text { theories [36] }\end{array}$ & $\begin{array}{l}\text { Showed how they selected different teaching method for } \\
\text { augmented reality application. }\end{array}$ & $\begin{array}{l}\text { Provided theoretical view with no experimental } \\
\text { justification. }\end{array}$ \\
\hline Construct 3D [25] & $\begin{array}{l}\text { (a) Run on heterogeneous and hybrid setups. (b) System was } \\
\text { built for mobile platform and collaborative. }\end{array}$ & $\begin{array}{l}\text { (a)Their laboratory set up cannot be fully implemented in } \\
\text { the schools or colleges, (b) They only aimed for geometry. }\end{array}$ \\
\hline AR Pop Up Book [27] & $\begin{array}{l}\text { Helped students to bridge the gap between digital and physical } \\
\text { world. }\end{array}$ & Experiment was conducted on only 5 students \\
\hline $\begin{array}{l}\text { Pre- } \& \text { post assessment survey } \\
\text { method [33] }\end{array}$ & $\begin{array}{l}\text { Better understand spatial concepts and make learning more } \\
\text { effective and interactive }\end{array}$ & This research is done only in grad 6-8 \\
\hline Applied methodology [3] & $\begin{array}{l}\text { Showed different types of AR application in educational } \\
\text { environment }\end{array}$ & No option to reproduce study. \\
\hline
\end{tabular}




\section{REVIEW BASED ON FRAMEWORKS}

Embedding AR in education to provide quality education is considered as challenging tasks task and researcher is still trying to find an optimal solution for which they tested and proposed many methods [39,40]. To prove those methods, they used some framework by which they intend to support their work which has proved to have better result in outcome. To support Multimodal Interface method researchers in [1] proposed Net mAR Framework which is divided into five phases, i.e. Phase 1: Conceptual Features to be applied on the application, Phase 2: Focus more on the software and hardware requirement to develop application, Phase 3: Prototype Development, Phase 4: Application Reliability Testing, Phase 5: Final Application. Advantages of the framework are motivating students in learning as well as helping them to retain the information longer, benefit the educator explaining more complex subjects to students and improve student's memorization capability through visualization [1]. However, drawback of the framework have is being a theory. To overcome this drawback, another framework was introduced for collaborative augmented reality system.

Collaborative augmented reality framework was based on collaborative construct 3D method which builds for collaboration of a large number of students and supports various teacher-student interaction scenarios. Collaborative augmented reality framework had hybrid hardware setups and provided a natural setting for face to face collaboration of teachers and students, projection walls were established techniques for semi-immersive group environment, and single projector display are affordable for classroom use [25]. Having all the advantages, collaborative augmented reality framework also comes with disadvantage. Due to the number of available AR sets significantly restricts the use in large groups and the screen is shared between the active user and the observer. To overcome these drawbacks AR Virtual Mirror Interface with socio-cultural theory framework can be used as remedy.

AR Virtual Mirror Interface with socio-cultural framework was built for affordance of AR virtual mirror and its advantage over head mounted system which describes the potentiality of $\mathrm{AR}$ in primary education [30]. In that research, framework needs four steps to implement, i.e. AR Sessions and recordings of the sessions, class teacher interview, data analysis, comparing teacher dialogue across AR and Traditional teaching sessions. Again, AR Virtual Mirror Interface with socio-cultural framework had issues like need to train teachers so that they do not fell out of script while teaching with new technology and limited observation time. To surpass this challenge, another framework is being proposed named as collaborative knowledge constructive framework.
TABLE II. PREVIOUS FRAMEWORKS WITH ADVANTAGES AND DISADVANTAGES

\begin{tabular}{|c|c|c|}
\hline $\begin{array}{l}\text { Previous } \\
\text { Frameworks }\end{array}$ & Advantages & Disadvantages \\
\hline $\begin{array}{l}\text { Quasi- } \\
\text { Experimental } \\
\text { Design } \\
\text { framework [4] }\end{array}$ & $\begin{array}{l}\text { (a)Academic Achievement } \\
\text { shows pre-\& post-test scores } \\
\text { differ significantly. (b) } \\
\text { Material motivation } \\
\text { questionnaires show that } \\
\text { motivation of the students } \\
\text { was high in positive } \\
\text { direction. (c) Fears of student } \\
\text { towards the Ottoman Turkish } \\
\text { Lesson were decreased. }\end{array}$ & $\begin{array}{l}\text { (a) Obtained data are } \\
\text { limited to the study group } \\
\text { and miracles group, (b) } \\
\text { AR integration was not } \\
\text { fully developed. }\end{array}$ \\
\hline $\begin{array}{l}\text { Net mAR } \\
\text { Framework [1] }\end{array}$ & $\begin{array}{l}\text { (a) Motivated students in } \\
\text { learning as well as helping } \\
\text { them retain the information } \\
\text { longer. (b) Benefited } \\
\text { educator in explaining more } \\
\text { complex objects to students, } \\
\text { (c) Improve memorization } \\
\text { through visualization }\end{array}$ & $\begin{array}{l}\text { Still in theoretical phase, } \\
\text { not in deployment. }\end{array}$ \\
\hline $\begin{array}{l}\text { AR Virtual } \\
\text { Mirror } \\
\text { Interface with } \\
\text { socio-cultural } \\
\text { theory } \\
\text { framework [30] }\end{array}$ & $\begin{array}{l}\text { (a) Affordance of AR virtual } \\
\text { mirror and its advantage over } \\
\text { head mounted system, (b) } \\
\text { Describes the potentiality of } \\
\text { AR in primary education. }\end{array}$ & $\begin{array}{l}\text { (a) Need to train teachers } \\
\text { so that they do not fell } \\
\text { out of script while } \\
\text { teaching with new } \\
\text { technology, (b) Students } \\
\text { less engaging with AR as } \\
\text { some of them holding AR } \\
\text { tiles and others are } \\
\text { observing, (c) Limited } \\
\text { time }\end{array}$ \\
\hline $\begin{array}{l}\text { Framework for } \\
\text { mARble } \\
{[31]}\end{array}$ & $\begin{array}{l}\text { (a) Students using mARble } \\
\text { showed better performance } \\
\text { than textbook, (b) Improved } \\
\text { learning rates. }\end{array}$ & $\begin{array}{l}\text { Only Basic medical } \\
\text { content were provided. }\end{array}$ \\
\hline $\begin{array}{l}\text { Collaborative } \\
\text { knowledge } \\
\text { constructive } \\
\text { framework [26] }\end{array}$ & $\begin{array}{l}\text { (a) Provided great } \\
\text { possibilities for supporting } \\
\text { face-to-face collaborative } \\
\text { learning, (b) Enhanced social } \\
\text { interactivity between or } \\
\text { among group learners, (c) } \\
\text { AR group learners performed } \\
\text { significantly better in terms } \\
\text { of their post-test scores. }\end{array}$ & $\begin{array}{l}\text { (a) While constructing } \\
\text { relations between single } \\
\text { theoretical concepts or } \\
\text { distinguished concepts } \\
\text { from each other, it would } \\
\text { confront obstacles } \\
\text { regarding the topic of } \\
\text { elastic collision and need } \\
\text { support from their } \\
\text { partners, (b) Other } \\
\text { dimensions such as the } \\
\text { argument and social } \\
\text { modes dimensions } \\
\text { needed to be analyzed. }\end{array}$ \\
\hline $\begin{array}{l}\text { Discovery } \\
\text { based learning } \\
\text { framework [38] }\end{array}$ & $\begin{array}{l}\text { Showed benefits of AR in } \\
\text { educational environments. }\end{array}$ & $\begin{array}{l}\text { Limited by a number of } \\
\text { factors, i.e. First, } \\
\text { identified empirical } \\
\text { studies are only informal } \\
\text { investigations with a low } \\
\text { number of participants. } \\
\text { The significance of the } \\
\text { ascertained benefits of } \\
\text { AR applications may be } \\
\text { unclear in these cases. } \\
\end{array}$ \\
\hline $\begin{array}{l}\text { Framework for } \\
\text { ARve [23] }\end{array}$ & Safe and highly portable & $\begin{array}{l}\text { Required further } \\
\text { experimental validation. }\end{array}$ \\
\hline
\end{tabular}


Collaborative knowledge constructive framework consists of various steps, i.e. Mobile AR in education, collaborative knowledge construction, enhancing learners understanding of elastic collision and momentum with technology, AR Physics system comparison with traditional 2D Physics, data analysis [26]. Collaborative knowledge constructive framework gave great possibilities for supporting face-to-face collaborative learning, enhancing social interactivity between or among group learners. AR group learners performed significantly better in terms of their post-test scores with disadvantages like while constructing relations between single theoretical concepts or distinguished concepts from each other, it would confront obstacles regarding the topic of elastic collision and need support from their partners. To overcome this challenge Quasi-Experimental Design framework was introduced.

Quasi-Experimental Design framework was based upon experimental method which takes a few steps to complete, i.e. research design, study group selection, data collection from the groups and finding representation. Material motivation questionnaires showed that motivation of the students was high in positive direction and fears of student towards the Ottoman Turkish Lesson were decreased [4]. Like all other framework, Quasi-Experimental Design framework also has some drawbacks, i.e. obtained data are limited to study group and AR technology was not fully developed. Previous frameworks with advantages and disadvantages for integrating augmented reality to improved existing education methodology are mentioned in Table II.

\section{REVIEW BASED ON EXPERIMENTS}

Augmented Reality is going to make education fun, increase student's motivation and will help them to improve their academic results as well. Having said that framework is the proof of the working methods, previous research conducted experiments to see if those methods or frameworks to validated their research, even if they have given some theoretical methods and frameworks, they proposed experimental steps so that if anyone implemented that framework they would know how to measure success or outcome of the experiments [41,42]. Research in [4] formed study groups, trained them with course materials, then conducted pre-\& post-test to see their methods effectiveness. They used academic and motivation questionnaires to measure the success of augmented reality. From their experiment with AR, pre-test result average was 29 and post-test result average was 56.4, which illustrates significant improvement with the help of augmented reality and states that augmented reality can help students to improve their results and increase motivation as well.

Augmented Reality can provide a great way for students to interact with the provided courses material and boost the engagement of students in classroom and keep them concentrated in the topic. Research in [30], tried to prove that by proposing a method called AR Virtual Mirror Interface. For their experiment they used web camera, AR tile, AR virtual mirror to set up the environment and by this system they taught students to prove the effectiveness of their research. They used several steps to run the experiment, i.e. AR sessions where they took AR sessions led by AR experienced teacher, own class teacher and recorded data. In the data analysis session, they used NUD*IST Quantitative analysis software to find results, they also recorded teachers interview to see teacher's reaction towards the system and use of Augmented reality in education.

Research in [32] conducted experiment to find AR contribution in improving education and integrate the technology in formal education. They made AR application to investigate how it could help students in discovery-based learning. To build their system environment, they used presentation devices, stimulus devices, tagging of known objects and computational estimators. Tagging of physical objects is what makes a device recognized a specific object in the real world. In their research, tagging of physical objects was accomplished with a system of GPS sensors, magnetic sensors, accelerometers, digital cameras, wireless sensors, digital compasses, and ultrasonic sensors. In their research, accuracy of a tagging system depended on the sensitivity of the various components where data processing components of AR systems required large amounts of RAM. Image capture was performed with a binocular or monocular lens. By analyzing their result, they found that highly accurate GPS position tracking to within 3 centimetres and accurately displayed results to users.

Research in [23] conducted their experiment to state the effectiveness for implementing augmented to visualize books. They built their system to integrate with primary school and used video projector, web cam, AR Book, webcam to scan the QR code from the AR book, and sent the findings to the video projector for visualization. In their application, participants had to complete several tasks, i.e. matching fruits, flower, seeds and leaves. Then they recorded the time to complete the task and analyzed the results. Their system was also compatible for handicapped students. Using their system $90 \%$ of the parents considered it positively for their teaching aspects. $97 \%$ of K-2 up to K-5 students finished 4 stages with fast and less training. Their results illustrate that augmented reality has great potentiality to be used in primary education.

Research in [28] proposed Realitat3 which consist of an AR engine and several AR applications, i.e. skeletal apparatus, water cycle, plant development, frog metamorphosis and solar system. They used camera calibration, marker detection and calculation of marker position and orientation (pose estimation). They tried to find out how AR games can be used to deliver education and increase student's spatial ability. 21 Students participated in their research experimentation and 95\% confidence level was gained using their proposed research. Previous research experimentation for integrating augmented reality to improved existing education methodology are mentioned in Table III. 
TABLE III. PREVIOUS RESEARCH EXPERIMENTATION

\begin{tabular}{|c|c|c|}
\hline $\begin{array}{l}\text { Previous research } \\
\text { methods }\end{array}$ & Parameter Used & Numeric Results \\
\hline $\begin{array}{l}\text { Experimental Method } \\
\text { [4] }\end{array}$ & $\begin{array}{l}\text { Academic \& Motivation } \\
\text { questionnaires' }\end{array}$ & $\begin{array}{l}\text { Academic result has } \\
\text { been increased. } \\
\text { Average Pre-Test } \\
\text { Score: } 29 \text {, Post- Test } \\
\text { Score: } 56.4 .\end{array}$ \\
\hline $\begin{array}{l}\text { AR Virtual Mirror } \\
\text { Interface with socio- } \\
\text { cultural theory [30] }\end{array}$ & $\begin{array}{l}\text { Teacher question in AR } \\
\text { sessions clarifying the } \\
\text { relationship between } \\
\text { elements on the screen, } \\
\text { Teacher question in AR } \\
\text { sessions: children turns } \\
\text { to hold a tile, Teacher } \\
\text { questions in the } \\
\text { traditional teaching } \\
\text { sessions, Teacher } \\
\text { interviews }\end{array}$ & $\begin{array}{l}96 \% \text { agreement } \\
\text { between AR } \\
\text { \&traditional teaching } \\
\text { transcript. }\end{array}$ \\
\hline $\begin{array}{l}\text { Four Step Research } \\
\text { Approach [42] }\end{array}$ & Benefits of AR & $\begin{array}{l}\text { Identified } 14 \text { different } \\
\text { benefits of AR in } \\
\text { education and among } \\
\text { them } 20 \% \text { benefits } \\
\text { were accounted for } \\
\text { Improved learning } \\
\text { curve and increased } \\
\text { motivation }\end{array}$ \\
\hline $\begin{array}{l}\text { Application Test } \\
\text { Method [32] }\end{array}$ & $\begin{array}{l}\text { Accuracy of a tagging } \\
\text { system }\end{array}$ & $\begin{array}{l}\text { (a) Highly accurate } \\
\text { GPS position tracking } \\
\text { to within } 3 \\
\text { centimetres. (b) } \\
\text { Accurately displays } \\
\text { results to users. }\end{array}$ \\
\hline $\begin{array}{l}\text { ARVe - Augmented } \\
\text { Reality applied to } \\
\text { Vegetal field [23] }\end{array}$ & $\begin{array}{l}\text { Accuracy to consider } \\
\text { positivity among users. }\end{array}$ & $\begin{array}{l}\text { (a) } 90 \% \text { of the parents } \\
\text { considered it positively } \\
\text { for their teaching } \\
\text { aspects. (b) } 97 \% \text { of K- } \\
2 \text { up to K-5 students } \\
\text { finished the } 4 \text { stages } \\
\text { with fast \& less } \\
\text { training }\end{array}$ \\
\hline Realitat3 [28] & $\begin{array}{l}\text { Number of participants } \\
\text { and confidence level. }\end{array}$ & $\begin{array}{l}\text { (a) } 21 \text { Students } \\
\text { participated in the } \\
\text { research, (b) 95\% } \\
\text { Confidence level using } \\
\text { application }\end{array}$ \\
\hline FreshAir $^{\mathrm{TM}}[24]$ & $\begin{array}{l}\text { Pre-field trip training } \\
\text { and post-field trip } \\
\text { discussion }\end{array}$ & $\begin{array}{l}70 \text { students were } \\
\text { participated in the } \\
\text { study }\end{array}$ \\
\hline $\begin{array}{l}\text { Cyberchase Shape } \\
\text { Quest [34] }\end{array}$ & Number of usages & $\begin{array}{l}\text { The game has been } \\
\text { downloaded more than } \\
500,000 \text { times }\end{array}$ \\
\hline
\end{tabular}

\section{OBSERVATION AND DisCUSSION}

Human have evolved by adapting new methods or new ways of living in the context of fourth industrial revolution, still we are doing same in every aspect of our life except for our existing education system. To keep our pace with fourth industrial revolution (IR 4.0) we need to identify the problems we are having with our education and how to integrate them with the help of technology. Augmented reality and virtual reality have proved to be a technological tool which is expected to improve current educational barrier. This research presents how previous research integrated augmented reality and virtual reality with education and observed some problems with their methods, framework and experiment.

From the review based on the method illustrates that augmented reality and virtual reality has really been showing its capability to provide quality education and fulfil the purpose with some drawbacks. In some of the methods, i.e. Experimental Method [4], Miracle System [5], mARble [31], One mouse per children [29], AR pop-up Book [27], Pre-\& Post Assessment Survey [3] researchers experimented their method for only a small proportion of population which gives them expected result but it cannot be said that the result will be the same when the experimentation for validation will be for large population. Again, in some of the methods, i.e. case study of AR in primary School [28], differentiate between learning theories [8] are only theoretical hypothesis with no experiment done. In review based on methods, i.e. Experimental Method [4], Miracle System [5], mARble [31], One mouse per children [29], Cybershape Chase Quest [34], AR physics [39] content was created for particular topic or based on small portion of the topic. In Construct 3D [25] method, proposed system setup was not idle for implementation as their setup was costly or not affordable for all. Again, in the basis of review based on methods, i.e. FreshAirTM[24] proposed system was environment oriented like indoor based augmented reality system which cannot be used in outdoor and outdoor based system cannot be implemented with indoor. In some reviews for the method illustrates that users found the system confusing causes less engagement for the participants or students.

Review based on framework showed same possibility with drawbacks. In Experimental Method Framework [4], AR was not fully developed to be integrated with education system. Net mAR Framework [1] was only in conceptual theory not implemented yet. In AR Virtual Mirror Interface with sociocultural theory [5] framework, to integrate augmented reality with education researchers need to teach teachers about the system so that they do not fell out of script while teaching. In other review based on framework, i.e. mARble [31], AR Virtual Mirror Interface [30], Application test method [32] illustrate that Augmented reality teaching materials was not fully developed which can only help to teach some particular subjects efficiently and deeply. In addition, sometimes there are some ethical problems, lack effectiveness when using with high-achieving students.

Review based on the experiment showed clear scenarios of augmented reality in education system in terms with validation. Based on the experimental results of some methods showed promising results, i.e. by using Experimental Method [4], academic results have been improved by $27.4 \%$ and using AR Virtual Mirror Interface [30] 96\% agreement has been reached between AR and traditional teaching transcript. Based on the four step research approach experiment mentioned in research [42], 14 benefits of AR found in education among them $20 \%$ benefits were accounted for improved learning curve and increased motivation. With ARve experiment [23], 90\% parents were satisfied with the usage of Augmented Reality. In addition, Realitat3 [28] received 95\% confidence level among students. 
Augmented reality and virtual reality has been used by different countries by different method. So far, in Chile and India Desktop application has been used to teach math to primary school student. In London also AR application was used to teach science subject, AR games are used to teach and improve spatial ability of primary school students. Spain used AR to teach geometry to primary school students. All of their efforts were fruitful and have illustrated improvements in engaging students with class material, boost activity, increased motivation, and memorization with visualization. To use augmented reality in primary education system AR books and AR application need to be used together as AR book will help them to teach history, literature subjects where AR Application with AR Games can teach them science, math and other subjects as well. In this way AR can be implemented in all the subjects to teach at primary level while making students motivated towards education, boost their engagement with class materials.

\section{CONCLUSION}

This research focused on integrating augmented reality and virtual reality into primary education to overcome current challenges of traditional educational method. This research illustrated thorough advantages and disadvantages for various methods to integrate augmented reality with primary education in the context of fourth industrial revolution (IR.0). Comprehensive reviews by this research show that if it is possible to integrate augmented reality and virtual reality with higher level of education, it can be integrated with primary education as well. Besides, demonstrated critical reviews by this research not only analyzed key points for the integration of augmented reality with primary education but also depicted hardware requirement to make overall research design for integration portable, cost effective, affordable which will help students to engage with the system easily. Although, augmented reality and virtual reality has been used by some countries, this research recommends to use AR books and AR application together as AR book can be used to teach one category of subjects such as history or literatures types of subjects and AR application can be used to teach science or math related subjects. This hybrid methodology is expected to improve students' motivation and engagement in class materials. Demonstrated reviews by this research are expected to play significant role in developing adaptive and collaborative education environment to fulfil the demand of fourth industrial revolution (IR 4.0).

\section{ACKNOWLEDGMENT}

The authors would like to thank Universiti Kebangsaan Malaysia for providing financial support under the "Geran Universiti Penyelidikan” research grant, GUP-2020-064.

\section{REFERENCES}

[1] A. F. Bulagang and A. B. Baharum, "A framework for developing mobile-augmented reality in higher learning education," Indian J. Sci. Technol, vol. 10, no. 39, pp. 1-8, 2017.

[2] J. L. Bacca Acosta, S. M. Baldiris Navarro, R. Fabregat Gesa, and S. Graf, "Augmented reality trends in education: a systematic review of research and applications," Journal of Educational Technology and Society, 2014, vol. 17, núm. 4, p. 133-149, 2014.

[3] K. Lee, "Augmented reality in education and training," TechTrends, vol. 56, no. 2, pp. 13-21, 2012.
[4] M. F. Özcan, Â. Özkan, and N. Sahin, "The Influence of the Augmented Reality Application on Students' Performances in Ottoman Turkish Readings," Universal Journal of Educational Research, vol. 5, no. n12B, pp. 27-33, 2017.

[5] T. Blum, V. Kleeberger, C. Bichlmeier, and N. Navab, "mirracle: An augmented reality magic mirror system for anatomy education," in 2012 IEEE Virtual Reality Workshops (VRW), 2012: IEEE, pp. 115-116.

[6] K. S. Tang, D. L. Cheng, E. Mi, and P. B. Greenberg, "Augmented reality in medical education: a systematic review," Canadian medical education journal, vol. 11, no. 1, p. e81, 2020.

[7] D. Chytas et al., "The role of augmented reality in anatomical education: An overview," Annals of Anatomy-Anatomischer Anzeiger, vol. 229, p. 151463, 2020.

[8] R. Salar, F. Arici, S. Caliklar, and R. M. Yilmaz, "A Model for augmented reality immersion experiences of university students studying in science education," Journal of Science Education and Technology, vol. 29, no. 2, pp. 257-271, 2020.

[9] E. E. Goff, A. Hartstone-Rose, M. J. Irvin, and K. L. Mulvey, "Using Augmented Reality to Promote Active Learning in College Science," in Active Learning in College Science: Springer, 2020, pp. 741-755.

[10] S. Su et al., "Virtual and augmented reality applications to support data analysis and assessment of science and engineering," Computing in Science \& Engineering, vol. 22, no. 3, pp. 27-39, 2020.

[11] N. Arulanand, A. R. Babu, and P. Rajesh, "Enriched learning experience using augmented reality framework in engineering education," Procedia Computer Science, vol. 172, pp. 937-942, 2020.

[12] A. S. Saif, A. S. Prabuwono, and Z. R. Mahayuddin, "Real time vision based object detection from UAV aerial images: a conceptual framework," in FIRA RoboWorld Congress, 2013: Springer, pp. 265-274.

[13] Z. R. MAHAYUDDIN and A. S. SAIF, "A COMPREHENSIVE REVIEW TOWARDS SEGMENTATION AND DETECTION OF CANCER CELL AND TUMOR FOR DYNAMIC 3D RECONSTRUCTION," Asia-Pacific Journal of Information Technology and Multimedia, vol. 9, no. 1, pp. 28-39, 2020.

[14] A. S. Saif, A. S. Prabuwono, and Z. R. Mahayuddin, "Motion analysis for moving object detection from UAV aerial images: A review," in 2014 International Conference on Informatics, Electronics \& Vision (ICIEV), 2014: IEEE, pp. 1-6.

[15] Z. R. Mahayuddin and A. S. Saif, "A Comprehensive Review Towards Appropriate Feature Selection for Moving Object Detection Using Aerial Images," in International Visual Informatics Conference, 2019: Springer, pp. 227-236.

[16] Z. R. Mahayuddin and A. S. Saif, "A COMPARATIVE STUDY OF THREE CORNER FEATURE BASED MOVING OBJECT DETECTION USING AERIAL IMAGES," Malaysian Journal of Computer Science, pp. 25-33, 2019.

[17] Z. R. Mahayuddin, A. S. Saif, and A. S. Prabuwono, "Efficiency measurement of various denoise techniques for moving object detection using aerial images," in 2015 International Conference on Electrical Engineering and Informatics (ICEEI), 2015: IEEE, pp. 161-165.

[18] A. S. Saif, A. S. Prabuwono, Z. R. Mahayuddin, and T. Mantoro, "Vision-based human face recognition using extended principal component analysis," International Journal of Mobile Computing and Multimedia Communications (IJMCMC), vol. 5, no. 4, pp. 82-94, 2013.

[19] A. Saif and Z. R. Mahayuddin, "Moving Object Segmentation Using Various Features from Aerial Images: A Review," Advanced Science Letters, vol. 24, no. 2, pp. 961-965, 2018.

[20] A. Saif, A. Prabuwono, and Z. Mahayuddin, "Adaptive long term motion pattern analysis for moving object detection using UAV aerial images," International Journal of Information System and Engineering, vol. 1, no. 1, pp. 50-59, 2013.

[21] A. Saif, A. S. Prabuwono, and Z. R. Mahayuddin, "Moving object detection using dynamic motion modelling from UAV aerial images," The Scientific World Journal, vol. 2014, 2014.

[22] A. S. Saif, A. S. Prabuwono, and Z. R. Mahayuddin, "Adaptive motion pattern analysis for machine vision based moving detection from UAV aerial images," in International Visual Informatics Conference, 2013: Springer, pp. 104-114. 
[23] E. Richard, V. Billaudeau, P. Richard, and G. Gaudin, "Augmented reality for rehabilitation of cognitive disabled children: A preliminary study," in 2007 virtual rehabilitation, 2007: IEEE, pp. 102-108.

[24] A. M. Kamarainen et al., "EcoMOBILE: Integrating augmented reality and probeware with environmental education field trips," Computers \& Education, vol. 68, pp. 545-556, 2013.

[25] H. Kaufmann and D. Schmalstieg, "Mathematics and geometry education with collaborative augmented reality," in ACM SIGGRAPH 2002 conference abstracts and applications, 2002, pp. 37-41.

[26] T.-J. Lin, H. B.-L. Duh, N. Li, H.-Y. Wang, and C.-C. Tsai, "An investigation of learners' collaborative knowledge construction performances and behavior patterns in an augmented reality simulation system," Computers \& Education, vol. 68, pp. 314-321, 2013.

[27] N. N. Mahadzir and L. F. Phung, "The use of augmented reality pop-up book to increase motivation in English language learning for national primary school," Journal of Research \& Method in Education, vol. 1, no. 1, pp. 26-38, 2013.

[28] G. Salvador-Herranz, D. Pérez-López, M. Ortega, E. Soto, M. Alcañiz, and M. Contero, "Manipulating virtual objects with your hands: A case study on applying desktop augmented reality at the primary school," in 2013 46th Hawaii International Conference on System Sciences, 2013: IEEE, pp. 31-39.

[29] C. Alcoholado et al., "One mouse per child: Interpersonal computer for individual arithmetic practice," Journal of Computer Assisted Learning, vol. 28, no. 4, pp. 295-309, 2012.

[30] L. Kerawalla, R. Luckin, S. Seljeflot, and A. Woolard, "“Making it real”: exploring the potential of augmented reality for teaching primary school science," Virtual reality, vol. 10, no. 3-4, pp. 163-174, 2006.

[31] U. Von Jan, C. Noll, M. Behrends, and U.-V. Albrecht, "mARbleaugmented reality in medical education," Biomedical Engineering/Biomedizinische Technik, vol. 57, no. SI-1-Track-A, 2012.

[32] G. Bitter and A. Corral, "The pedagogical potential of augmented reality apps," International Journal of Engineering Science Invention, vol. 3, no. 10, pp. 13-17, 2014

[33] P. S. Medicherla, G. Chang, and P. Morreale, "Visualization for increased understanding and learning using augmented reality," in
Proceedings of the international conference on Multimedia information retrieval, 2010, pp. 441-444.

[34] I. Radu, E. Doherty, K. DiQuollo, B. McCarthy, and M. Tiu, "Cyberchase shape quest: pushing geometry education boundaries with augmented reality," in Proceedings of the 14th international conference on interaction design and children, 2015, pp. 430-433.

[35] H.-K. Wu, S. W.-Y. Lee, H.-Y. Chang, and J.-C. Liang, "Current status, opportunities and challenges of augmented reality in education," Computers \& education, vol. 62, pp. 41-49, 2013.

[36] B. Parhizkar, W. K. Obeidy, S. A. Chowdhury, Z. M. Gebril, M. N. A. Ngan, and A. H. Lashkari, "Android mobile augmented reality application based on different learning theories for primary school children," in 2012 International Conference on Multimedia Computing and Systems, 2012: IEEE, pp. 404-408.

[37] K. R. Bujak, I. Radu, R. Catrambone, B. MacIntyre, R. Zheng, and G. Golubski, "A psychological perspective on augmented reality in the mathematics classroom," Computers \& Education, vol. 68, pp. 536-544, 2013.

[38] P. Diegmann, M. Schmidt-Kraepelin, S. Eynden, and D. Basten, "Benefits of augmented reality in educational environments-a systematic literature review," Benefits, vol. 3, no. 6, pp. 1542-1556, 2015.

[39] Z. Mahayuddin and A. Saif, "Efficient Hand Gesture Recognition Using Modified Extrusion Method based on Augmented Reality," TEST Engineering and Management, vol. 83, pp. 4020-4027, 2020.

[40] Z. R. Mahayuddin and A. Saif, "Augmented Reality Based Ar Alphabets Towards Improved Learning Process In Primary Education System," Journal of Critical Reviews, vol. 7, no. 19, pp. 514-521, 2020.

[41] A. S. Saif, A. S. Prabuwono, and Z. R. Mahayuddin, "Moment feature based fast feature extraction algorithm for moving object detection using aerial images," PloS one, vol. 10, no. 6, p. e0126212, 2015.

[42] A. S. Saif, A. S. Prabuwono, Z. R. Mahayuddin, and H. T. Himawan, "A review of machine vision based on moving objects: object detection from UAV aerial images," International Journal of Advancements in Computing Technology, vol. 5, no. 15, p. 57, 2013. 